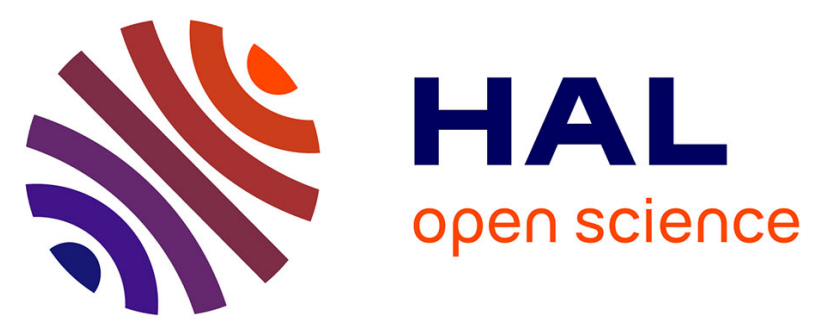

\title{
Prospective Assessment of the Sexual Function After Greenlight Endoscopic Enucleation and Greenlight 180W XPS Photoselective Vaporization of the Prostate
} Romain Huet, Benoit Peyronnet, Zine-Eddine Khene, Lucas Freton, Grégory Verhoest, Andréa Manunta, Karim Bensalah, Sébastien Vincendeau, Romain Mathieu

\section{To cite this version:}

Romain Huet, Benoit Peyronnet, Zine-Eddine Khene, Lucas Freton, Grégory Verhoest, et al.. Prospective Assessment of the Sexual Function After Greenlight Endoscopic Enucleation and Greenlight 180W XPS Photoselective Vaporization of the Prostate. Urology, 2019, 131, pp.184 - 189. 10.1016/j.urology.2019.06.020 . hal-03487726

\author{
HAL Id: hal-03487726 \\ https://hal.science/hal-03487726
}

Submitted on 20 Dec 2021

HAL is a multi-disciplinary open access archive for the deposit and dissemination of scientific research documents, whether they are published or not. The documents may come from teaching and research institutions in France or abroad, or from public or private research centers.
L'archive ouverte pluridisciplinaire HAL, est destinée au dépôt et à la diffusion de documents scientifiques de niveau recherche, publiés ou non, émanant des établissements d'enseignement et de recherche français ou étrangers, des laboratoires publics ou privés.

\section{(ㄷ)(1) $\$$}

Distributed under a Creative Commons Attribution - NonCommerciall 4.0 International 


\section{PROSPECTIVE ASSESSEMENT OF THE SEXUAL FUNCTION AFTER GREENLIGHT $^{\text {TM }}$ ENDOSCOPIC ENUCLEATION AND GREENLIGHT $^{\text {TM }}$ 180W XPS PHOTOSELECTIVE VAPORIZATION OF THE PROSTATE}

Romain HUET ${ }^{1}$, Benoit PEYRONNET* 1, Zine-Eddine KHENE 1, Lucas FRETON 1 , Grégory VERHOEST 1, Andréa MANUNTA 1, Karim BENSALAH ', Sébastien VINCENDEAU ${ }^{1}$, Romain MATHIEU ${ }^{1}$

${ }^{1}$ Department of Urology, Rennes University Hospital, University of Rennes 1, France

${ }^{*}$ Corresponding author:

Dr Benoit PEYRONNET, MD

Department of Urology, Rennes University Hospital

2 rue Henri Le Guilloux, 3500 Rennes, France.

Phone : 0033665717254

Mail: peyronnetbenoit@hotmail.fr

Keywords: laser; sexual function; prostate; enucleation; vaporization

Word count: 2638

\section{Conflicts of interest}

Benoit PEYRONNET and Sébastien VINCENDEAU are consultants for Boston Scientific 


\section{INTRODUCTION}

Sexual dysfunction is commonly encountered in men with Low Urinary Tract Symptoms (LUTS) [1]. Probably underestimated, sexual activity was reported in $83 \%$ of men over 50 years old. LUTS due to Benign Prostate Obstruction (BPO) increases from $50 \%$ of men aged fifty to $80 \%$ of men over 70 years old. Many men with medical therapy require a surgical approach at some point due to prostatic volume progression and nature of the disease [2]. According to European Association of Urology and American Urology Association guidelines, Holmium Laser enucleation of the prostate (HoLEP) may be the preferred minimally invasive surgical treatment option for prostates larger than $80 \mathrm{~g}[3,4]$. However, this surgical approach requires experience and relevant endoscopic skills that could explain its relatively slow widespread over the past decade [5]. Other minimally laser techniques have been developed, such as photoselective vaporization of the prostate (PVP) with Greenlight $^{\mathrm{TM}}$ laser 180W [6], whose safety and efficacy in prostates $>80 \mathrm{ml}$ have been reported in expert medical centers $[7,8]$. Recently, endoscopic enucleation of the prostate with Greenlight ${ }^{\mathrm{TM}}$ laser (GreenLEP) has been described as a possibly better approach than PVP 180W in larger prostates in terms of postoperative PSA decrease and risk of surgical re-treatment $[9,10]$.

The effects of PVP 180W and GreenLEP on sexual function have never been assessed so far. Sexual impact of transuretral resection of the prostate (TURP) is controversial [11]. Regarding HoLEP, recent studies described a stable sexual function after surgery, despite high prevalence of ejaculatory dysfunction [12]. A maintained sexual function after PVP 80W and 120W was also reported using the International Index of Erectile Function (IIEF-5) [13].

The aim of this study was to assess the sexual impact (i.e. impact on ejaculatory and erectile functions (EF)) of PVP Greenlight ${ }^{\mathrm{TM}} 180 \mathrm{~W}$ and GreenLEP.

\section{MATERIALS AND METHODS}

\section{Study design}

Between January 2014 and September 2016, the data of 440 consecutive men with LUTS or complications related to BPO who underwent a PVP or GreenLEP at our 
institution were prospectively collected. Surgical indications were based on guidelines of the European Association of Urology (EAU) [4]. Patients with prostate volume $<80 \mathrm{~g}$ on preoperative trans-rectal ultrasonography (TRUS) were excluded as well as patients with a post-operative follow-up $<12$ months, preoperative IIEF5 score $<5$ (not sexually active), a history of neurological disorder or pelvic radiotherapy, untreated urinary tract infection, history of previous urethral surgery, prostate cancer (PSA $>4 \mathrm{ng} / \mathrm{ml}$ and positive prostate biopsy or suspect digital-rectal examination), and procedures performed by low experienced surgeons $(<100$ procedures).

\section{$\underline{\text { Interventions }}$}

Patients with antiplatelet therapy were operated under aspirin only (i.e. clopidogrel was always stopped during the perioperative period). Oral anticoagulation was bridged to low molecular weight heparin throughout the perioperative period in patients with high risk of thrombotic event and stopped in the others. PVP was performed with Greenlight ${ }^{\mathrm{TM}}$ 180-W XPS (Boston Scientific System ${ }^{\mathrm{TM}}$; Inc. USA) and the MoXy laser fiber. Surgical technique was based on optimization of laser energy delivered to the prostatic tissue. After the completion of two channels at 5 and 7 o'clock with an energy setting of $80 \mathrm{~W}$, median lobe was first vaporized. Then, lateral lobes were removed using an energy setting of 80 to $140 \mathrm{~W}$ towards the surgical capsule. The surgical objective was a widely open prostate cavity based with concomitant TRUS of the prostate during our initial experience [14].

GreenLEP was performed as previously described by Gomez-Sancha's using the HPS-120W fiber and 532nm 180W generator [9]. After a circonferential incision at the verumontanum, the adenoma at the apex was removed from the external sphincter. Then, the "en-bloc" enucleation was performed through a blunt dissection between the adenoma and the capsule with the tip of the scope from the apex to the bladder neck. Once removed, "en-bloc" adenoma was placed into the bladder and morcellated using Wolf ${ }^{\mathrm{TM}}$ morcellator and Wolf Pyrana ${ }^{\mathrm{TM}}$ endoscop (Richard Wolf $\mathrm{GMbH}^{\mathrm{TM}}$, Knittlingen, Germany). At last, retrieved tissue were weighted and examined histologically.

\section{$\underline{\text { Outcomes }}$}


The patients' characteristics, perioperative parameters and complications were prospectively collected. Postoperative complications were defined as any medical or surgical adverse event within the first 30 days following surgery using the ClavienDindo's classification modified according to the Greenlight ${ }^{\mathrm{TM}}$ Users Group (GUGL) [15]. Sexual parameters involved antegrade ejaculation status (persistent or not) and International Index of Erectile Function-5 (IIEF5 score). Patients were evaluated at the third month after surgery and annually thereafter. Functional outcomes using questionnaires (IIEF5 score, IPSS score, QoL from IPSS scores and ICS male SF score), uroflowmetry and PSA were collected. Post-void residual (PVR) was assessed using supra-pubic ultra-sonography. Re-treatment was defined as any LUTS related to benign prostate obstruction (BPO) that required medical or surgical treatment.

The primary outcome was the change in erectile function (subjectively defined as any postoperative decline of IIEF5 $\geq 5$ points) [16]. The secondary outcomes were changes in voiding parameters ( $\Delta$ Nocturia, maximum flow rate (Qmax), post-void residual urine volume (PVM), International Prostate Symptom Score ( $\triangle$ IPSS score), Quality of Life question $8(\mathrm{QoL})$ from IPSS, International Continence Society male SF score and urinary incontinence questions from the ICS male SF score.

\section{Statistical analysis}

Patients were matched in a 1:1 fashion according to the following variables: preoperative trans-rectal ultrasonography prostatic volume (PV) and cardiovascular risk factors (any of the following: smoking, diabetes and hypertension). Continuous variables were reported as mean and standard deviation (SD). Comparisons of continuous and categorical variables were performed using the Mann-Whitney U-test and $\chi^{2}$-square (or Fisher's exact test, as appropriate), respectively. Logistic regression analysis was used to assess predictive factors of $\triangle$ IIEF5 $\geq-5$. Spearman's rho assessed the correlation between continuous variables. Long term re-treatment rate free survival estimates were generated using Kaplan-Meier method; Log-rank was applied for pairwise comparison of survival. McNemar test assessed the paired variations of IIEF5 in each group. All $p$ values were two-sided and statistical significance was defined as a $p \leq 0.05$. The statistical analysis was performed with $J_{M P}{ }^{T M}$ v.12.0 software (SAS Institute Inc, Cary, NC, USA). 


\section{RESULTS}

\section{Patient characteristics}

The patient characteristics are summarized in table 1. Regarding ASA score, hypertension, smoking status, and history of diabetes, GreenLEP and PVP groups were comparable $(p=0.28, p=0.90, p=0.79$ and $p=0.59$, respectively). The mean age was 68 years $(95 \% \mathrm{Cl}: 66-70)$ and $33 / 200(17.7 \%)$ of patients were catheterdependent before surgery.

\section{Perioperative outcomes}

The intraoperative data and postoperative results are shown in supplementary table 1. Mean preoperative prostate volume was $110 \mathrm{~g}$ (95\% $\mathrm{Cl}:$ 101-118) and $107 \mathrm{~g}$ (95\%Cl: 99-115) in the GreenLEP and PVP groups, respectively ( $\mathrm{p}=0.68)$. Mean total energy delivered in the PVP group was $4.42 \mathrm{KJ} / \mathrm{gram}$ (4.2-4.6). Mean enucleation and morcellation times were $54 \mathrm{~min}(95 \% \mathrm{Cl}: 40-60)$ and $14 \mathrm{~min}$ (11-17), accounting for $63 \%$ and $16 \%$ of total operative time, respectively. Mean prostate tissue enucleated was $75.1 \pm 38.7$ grams according to final pathology. Total operative time was significantly longer in the GreenLEP group compared to the PVP group ( $p=0.03$ ). Irrigation, catheter and hospitalization times were comparable in both groups $(p=0.79, p=0.32$ and $p=0.11$, respectively). $98.9 \%$ of patients in GreenLEP group recovered spontaneous voiding after surgery vs. $88.5 \%$ in the PVP group $(p=0.002)$. The rates of postoperative complications were comparable in the two groups $(p=0.93)$.

\section{Urinary and anatomical outcomes}

Regarding baseline IPSS score, nocturia and Qmax, no statistically differences were observed between the two groups $(p=0.33, p=0.29$ and $p=0.27$, respectively). All urinary outcomes favored the GreenLEP group (supplementary table 2). IPSS score was significantly lower in the GreenLEP group than in the PVP group at 3, 12 and 24 months postoperatively $(p<0.001)$. The postoperative IPSS-Qol evolution favored the GreenLEP group as well $(p=0.003, p=0.007$ and $p<0.001$ at 3,12 and 24 months respectively). Compared to the GreenLEP group, nocturia evolution postoperatively in the PVP group was poorer with a mean variation of $0.5 \pm 1.5,0.8 \pm 1.6$ and $0.9 \pm 0.2$ 
at 3, 12 and 24 months, respectively $(p<0.05)$. The $Q \max$ was significantly greater in GreenLEP group at each time point $(p<0.001, p=0.003$ and $p=0.003)$.

Initial PSA levels were similar in the two groups $(p=0.64)$ (supplementary table 3 and Figure 1). Mean reductions of PSA levels were $81.3 \%$ and $63.2 \%$ after 3 months, $73.4 \%$ and $54.4 \%$ after 12 months, $73.4 \%$ and $33.8 \%$ after 24 months, in the GreenLEP and PVP groups, respectively $((p<0.001, p=0.026$ and $p=0.004)$. After a mean follow up of 25.1 and 18.6 months, re-treatment rate was needed in nine patients (10.1\%) in the PVP group vs. no patient in the GreenLEP group (log rank test: $p=0.002)$.

\section{Impact on sexual functions}

Antegrade ejaculation was reported as being preserved in 24 patients $(26.9 \%)$ in the PVP group vs one patient $(1.2 \%)$ in the GreenLEP group at 12 months $(p<0.001)$. Postoperative IIEF5 evolution was reported in Table 2. At baseline, IIEF5 scores were comparable in both groups $(\mathrm{p}=0.62)$. In the GreenLEP group, IIEF5 increased from 1.1 point, 1.3 and 0.7 point at 3,12 and 24 months postoperatively. In the PVP group, IIEF5 remained stable after 3 months and decreased significantly after 12 and 24 months $(p=0.031)$.

An IIEF5 decline $\geq 5$ points was observed in two and 19 patients in the GreenLEP and PVP groups, respectively $(p<0.001)$. The mean postoperative change in IIEF5 favored GreenLEP at each time point, being +1.1 vs. -0.6 at 3 months $(p<0.0001)$; +1.3 vs. -1.3 at 12 months $(p<0.0001)$ and +0.8 vs. -1.3 at 24 months $(p=0.008)$.

In multivariate analysis (adjusted to BMI, smoking, hypertension and diabetes status, $\Delta$ Nocturia $>2$ and $\Delta$ IPSS $<5$ ) age, history of coronary artery disease and surgical treatment with PVP (vs. GreenLEP) were independent predictors of IIEF5 decline over 5 points (Table 3 ).

Only the GreenLEP resulted in statistically significant improvement of IIEF5 at each postoperative assessment compared to baseline $(p=0.002)$. Using Spearman correlation, we found a significant correlation between $\Delta$ Nocturia and $\Delta$ IIEF-5 $(r=-$ $0.574 p<0.0001)$ and between $\Delta$ IPSS and $\Delta$ IIEF-5 $(r=0.273 p=0.0006)$ at 3 months. 


\section{DISCUSSION}

The present study is the first prospective evaluation of sexual function after surgical treatment of BPO due to larger prostates. We observed an improvement of erectile function in the GreenLEP group while the erectile function worsened over time with recurring LUTS after PVP. PVP (vs. GreenLEP) was also a predictor of significant IIEF5 decrease posoperatively ( $\geq 5$ points) in multivariate analysis. Surgical technique seemed to be an independent factor of the postoperative evolution of EF. Elshal et al. reported an improvement of EF compared to the control group with HoLEP in patients with a mean prostate volume of $132 \pm 54$ grams [12]. However, in a subgroup of patients with a normal baseline IIEF5 score, EF had decreased at the $12^{\text {th }}$ month of follow-up. The same author described in a previous study a decline of EF in $17.2 \%$ of HoLEP group vs $29.3 \%$ of patients in the PVP group [16]. Univariate analysis had identified baseline IIEF5 score as an independent factor of erectile function decline. In our study, two patients in the GreenLEP group and nineteen in the PVP group had a lowered postoperative EF score $(p<0.001)$. Interestingly, mean initial IIEF5 in these patients was $19.7 \pm 4.8$ vs $13.1 \pm 6.7(p<0.001)$. With monopolar or bipolar TURP, Akman et al. also showed $17.0 \%$ of patients with worsening EF after surgery [17]. This finding has also been reported after PVP. Most studies showed a comparable baseline vs. postoperative EF [18]. However, Bruyere et al. and Kumar et al. reported a significant decrease in IIEF5 score in the sub-group of men with normal baseline EF $[13,19]$. Underlying assumptions were thermal damage to proximal cavernosal nerves during procedures, and the role of cardiovascular comorbidity such as diabetes [20]. We could easily explain a surgical stress in the early postoperative period in patients with normal initial EF, affecting their sexual life.

Erectile function remains a narrow vision of sexual life [21]. There is multidimensional aspects of the sexuality, desire or libido, orgasm, happiness, ejaculatory function that are not addressed by an erectile score such as the IIEF5 [22]. The present study reported a rate of antegrade ejaculation in $26.9 \%$ and $1.2 \%$ of patients in PVP and GreenLEP groups, respectively. Conversely the evolution of IIEF5 score postoperatively favored the GreenLEP group. For urologists, main objective in the management of LUTS due to larger prostates remains an anatomic treatment of the 
adenoma to avoid the risk of recurring LUTS due to residual adenoma and a compromise with persistent antegrade ejaculation [9]. Since McVary's works, relationship between LUTS and ED are now acknowledged by all [23]. Nitric oxide (NO) decrease in prostate and penile smooth muscle remains the pharmacological target of PDE5-inhibotors in LUTS and DE medical treatments [24].

In our cohort, initial prostate volumes were comparable in both groups. Mean energy delivered in PVP group was $4.42 \mathrm{KJ} / \mathrm{gram}$. In an international multicenter study, energy delivered over $3 \mathrm{KJ} / \mathrm{gram}$ provided a PSA reduction over 50 percent. Higher energy $>7 \mathrm{KJ} / \mathrm{g}$ seemed to reduce PSA up to $83 \%$. Using high energy density was not associated with higher rate of perioperative complications [25]. The same rate of re-treatment was observed all groups. Postoperative PSA reduction is considered as a great surrogate of the prostatic volume treated for Greenlight users.

Actually, there are few studies showing the outcome of GreenLEP. Among them, GreenLEP seemed to have a superiority in term of re-treatment rate [26]. In our study, ten percent of patients in the PVP group required another medical or surgical treatment of LUTS after a median follow-up of 25.1 months. Using PVP 180W laser, Meskawi et al. recently reported in a multicenter study a re-treatment rate of $5.4 \%$ and $9.3 \%$ at 24 and 36 months, respectively [27]. Hueber et al. reported this rate from 1.0 to 1.2 at 12 and 24 months of follow-up, respectively, Calves et al., a rate of $4.8 \%$ with a mean follow-up of $57.4 \pm 6.8$ months in smaller prostate volumes [7] [28]. Most of these re-treated patients experienced a lower energy delivered to the tissue, a lower postoperative PSA reduction and had a higher prostate volume. Our findings reinforce the existing evidence regarding the poor reliability of PVP in larger prostates with high retreatment rate in the medium to long run.

Our poorer outcomes regarding EF and IIEF-5 in the PVP group could be explained by this rate of re-treatment and recurring LUTS. This relationship was underlined with statically correlation between postoperative $\Delta$ Nocturia, $\Delta$ IPSS and $\Delta$ IIEF-5 $(p<0.0001$ and $p<0.0006$, respectively). This association between LUTS and EF is well depicted in many epidemiologic studies [1]. 
Cardiovascular disease (CVD), age, hypertension and coronary disease, were also reported as predictive factors of worsening EF. Erectile dysfunction (ED) and CVD share common risk factors included diabetes, hypertension, age, obesity, metabolic syndrome hypercholesterolemia, sedentary lifestyle and depression [29]. They also share the same pathophysiology basis. Despite atherosclerotic burden, subclinical cavernosal inflammation, endothelial dysfunction and androgen deprivation interactions were clearly advocated. According to the "artery size" hypothesis, the smaller penile arteries suffer earlier than larger coronary arteries [30]. ED is now recognized as an early predictor of coronary artery disease [29].

The present study has several limitations that should be acknowledged. We evaluated the impact of modern and minimally laser treatments in BPO-related LUTS using PVP 180W and GreenLEP with a minimal erectile function score (IIEF-5) and ejaculatory status alone. Larger sexual function scores as IIEF-15 score, Danish Prostatic Symptom Score (Dan-PSS-Sex) or Ej-MSHQ (Ejaculation domain-male sexual health questionnaire) may have provided a more appropriate assessement of sexual function. Moreover, although statistically significant, the clinical significance of the difference in post-operative IEEF 5 evolution between the two groups could be called into question. Another possible shortcoming is that follow-up was not comparable in both groups with only 18.6 months in the GreenLEP group. A prospective controlled study could provide a more accurate comparative evaluation of the sexual impact of these two surgical procedures. The relatively limited number of events for the primary outcomes (21 patients had a decline of more than 5 points in the IIEF5) resulted in an underpowered multivariate assessment. Finally, owing to the increasing evidence on the poorer outcomes of PVP in larger glands, the two techniques compared herein (PVP and GreenLEP) could be seen as indicated for different patients' population and the clinical relevance of their comparison could therefore be regarded as debatable.

\section{CONCLUSION}

In this first prospective comparison of erectile function after surgical treatment of BPO due to larger prostates, we found a significant improvement of IIEF5 
postoperatively in the GreenLEP group despite a poor rate of preserved antegrade ejaculation. Conversely erectile function slightly declined in the PVP group over time, concomitantly to recurring LUTS. Age, history of CAD, and surgical treatment of BPO with PVP (vs. GreenLEP) were independent predictors of significant IIEF5 decline ( $\geq$ 5). Further studies are needed to confirm our findings and the potential impact of recurring LUTS after PVP on erectile function.

\section{REFERENCES}

1. Rosen RC, Giuliano F and Carson CC: Sexual Dysfunction and Lower Urinary Tract Symptoms (LUTS) Associated with Benign Prostatic Hyperplasia (BPH). European Urology 2005; 47: 824-837.

2. Roehrborn CG: Current Medical Therapies for Men With Lower Urinary Tract Symptoms and Benign Prostatic Hyperplasia: Achievements and Limitations. Rev Urol 2008: 1-12.

3. McVary KT, Roehrborn CG, Avins AL, Barry MJ, Bruskewitz RC, Donnell RF, Foster HE, Gonzalez CG, Kaplan SA, Penson DF, Ulchaker JC and Wei JT. Update on AUA Guideline on the Management of Benign Prostatic Hyperplasia. Journal of Urology 2011; 185: 1793-1803.

4. Gratzke C, Bachmann A, Descazeaud A, Drake MJ, Madersbacher S, Mamoulakis C, Oelke M, Tikkinen KAO, Gravas S. EAU Guidelines on the Assessment of Non-neurogenic Male Lower Urinary Tract Symptoms including Benign Prostatic Obstruction. European Urology 2015: 1-11.

5. Peyronnet B, Robert G, Comat V, Rouprêt M, Gomez-Sancha F, Cornu J-N, Misrai V. Learning curves and perioperative outcomes after endoscopic enucleation of the prostate: a comparison between GreenLight 532-nm and holmium lasers. World J Urol 2016; 35: 973-983. 
6. Cornu J-N, Ahyai S, Bachmann A, de la Rosette J, Gilling P, Gratzke C, McVary K, Novara G, Woo H, Madersbacher S. A Systematic Review and Meta-analysis of Functional Outcomes and Complications Following Transurethral Procedures for Lower Urinary Tract Symptoms Resulting from Benign Prostatic Obstruction: An Update. European Urology 2014: 1-31.

7. Hueber P-A, Bienz MN, Valdivieso R, Lavigueur-Blouin H, Misrai V, Rutman M, Te AE, Chughtai B, Barber NJ, Emara AM, Munver R, Trinh QD, Zorn KC. Photoselective Vaporization of the Prostate for Benign Prostatic Hyperplasia Using the 180 Watt System: Multicenter Study of the Impact of Prostate Size on Safety and Outcomes. Journal of Urology 2015; 194: 462-469.

8. Castellan P, Castellucci R, Schips L, Cindolo L. Safety, efficacy and reliability of 180-W GreenLight laser technology for prostate vaporization: review of the literature. World J Urol 2015; 33: 599-607.

9. Gomez Sancha F, Rivera VC, Georgiev G, Botsevski A, Kotsev J, Herrmann T. Common trend: move to enucleation-Is there a case for GreenLight enucleation? Development and description of the technique. World J Urol 2014; 33: 539-547.

10. Misrai V, Kerever S, Phe V, Zorn KC, Peyronnet B, Roupret M. Direct Comparison of GreenLight Laser XPS Photoselective Prostate Vaporization and GreenLight Laser En Bloc Enucleation of the Prostate in Enlarged Glands Greater than $80 \mathrm{ml}$ : a Study of 120 Patients. Journal of Urology 2016; 195: 1027-1032.

11. Emberton $M$, Neal $D E$, Black $N$, Fordham $M$, Harrison $M$, McBrien MP, Williams RE, McPherson K, DEvlin HB. The effect of prostatectomy on symptom severity and quality of life. $\mathrm{Br} \mathrm{J}$ Urol 1996; 77: 233-247.

12. Elshal AM, El-Assmy A, Mekkawy R, Taha DE, El-Nahas AR, Laymon A, ElKappany $\mathrm{H}$, Ibrahiem EH. Prospective controlled assessment of men's sexual function changes following Holmium laser enucleation of the prostate for treatment of benign prostate hyperplasia. International Urology and Nephrology 2017: 1-9.

13. Bruyere F, Puichaud A, Pereira H, Faivre d'Arcier B, Rouanet A, Floc'h AP, Bodin T, Brichart N. Influence of Photoselective Vaporization of the Prostate on Sexual Function: Results of a Prospective Analysis of 149 Patients with LongTerm Follow-Up. European Urology 2010; 58: 207-211.

14. Huet R, Mathieu R, Rohou T, Peyronnet B, Manunta B, Verhoest K, Bensalah K, Vincendeau S. MRI assessment of tissue effects after 180-W XPS greenlight laser vaporization of the prostate. Lasers Surg. Med. 2017; 49: 577581.

15. Peyronnet B, Pradere B, Brichart N, Bodin T, Bertrand P, The Members of the French Group of GreenLight Users, Bruyère F. Complications Associated With Photoselective Vaporization of the Prostate: Categorization by a Panel of GreenLight Users According to Clavien Score and Report of a Single-center 
Experience. Urology 2014; 84: 657-664.

16. Elshal AM, Elmansy HM, Elkoushy MA, Elhiali M. Male Sexual Function Outcome After Three Laser Prostate Surgical Techniques: A Single Center Perspective. Urology 2012; 80: 1098-1104.

17. Akman T, Binbay M, Tekinarslan E, Tepeler A, Akcay M, Ozgor F, Ugurlu M, Muslumanoglu A. Effects of bipolar and monopolar transurethral resection of the prostate on urinary and erectile function: a prospective randomized comparative study. BJU Int 2012; 111: 129-136.

18. Terrasa JB, Cornu JN, Haab F, Cussenot O, Lukacs B. Prospective, Multidimensional Evaluation of Sexual Disorders in Men after Laser Photovaporization of the Prostate. The Journal of Sexual Medicine 2013; 10: 1363-1371.

19. Anup K, Pawan V, Niraj K, Biswajit N, Nayan K M. Evaluation of the Effect of Photoselective Vaporization of the Prostate on Sexual Function in a Prospective Study: A Single Center Experience of 150 Patients. Journal of Endourology 2012: 1-5.

20. Walsh PC, Lepor $\mathrm{H}$, and Eggleston JC. Radical prostatectomy with preservation of sexual function: anatomical and pathological considerations. Prostate 1983.

21. Giuliano F: Neurophysiology of Erection and Ejaculation. The Journal of Sexual Medicine 2011; 8: 310-315.

22. Lukacs B. Assessment of male sexual function. Prostate Cancer and Prostatic Diseases 2001: 1-5.

23. McVary KT, Gange SN, Gittelman MC, Goldberg KA, Patel K, Shore ND, Levin $\mathrm{RM}$, Rousseau M, Beahrs JR, Kaminetsky J, Cowan BE, Cantrill $\mathrm{CH}$, Mynderse LA, Ulchaker JC, Larson TR, Dixon CM, Roehrborn CG. Response and Rebuttal to Editorial Commentary on "Erectile and Ejaculatory Function Preserved With Convective Water Vapor Energy Treatment of Lower Urinary Tract Symptoms Secondary to Benign Prostatic Hyperplasia: Randomized Controlled Study". The Journal of Sexual Medicine 2016; 13: 936-937.

24. Gacci M, Andersson K-E, Chapple C, Maggi M, Mirone V, Oelke M, Porst H, Roehrborn C, Stief C, Giuliano F. Latest Evidence on the Use of Phosphodiesterase Type 5 Inhibitors for the Treatment of Lower Urinary Tract Symptoms Secondary to Benign Prostatic Hyperplasia. European Urology 2016: $1-10$.

25. Valdivieso R, Meyer CP, Hueber P-A, Meskawi M, Alenizi AM, Azizi M, Trinh $\mathrm{QD}$, Misrai V, Rutman M, Te AE , Chughtai B, Barber NJ, Emara AM, Munver $\mathrm{R}$, Zorn KC. Assessment of energy density usage during $180 \mathrm{~W}$ lithium triborate laser photoselective vaporization of the prostate for benign prostatic hyperplasia. Is there an optimum amount of kilo-Joules per gram of prostate? BJU Int 2016; 118: 633-640. 
26. Huet R, Vincendeau S, Sebe P, Guillonneau B, Colau A, Verhoest G, Bensalah K, Peyronnet B, Mathieu R. PD27-09 Photoselective Vaporization of the Prostate with Greenlight Laser XPS 180W, Green Laser Enucleation of the Prostate and Open Prostatectomy for Benign Prostate Obstruction: a comparative analysis of perioperative and short term results. The Journal of Urology 2017; 197: e514-e515.

27. Malek M, Hueber PA, Valdivieso R, Bruyere F, Misrai V, Fournier G, Munver R, Sivarajan G, Rutman M, Te AE, Chughtai B, Elterman D, Martel T, Azizi M, Karakiewicz PI, Zorn KC. Multicenter international experience of $532 \mathrm{~nm}$-laser photo- vaporization with Greenlight XPS in men with large prostates (prostate volume > $100 \mathrm{cc}$ ). World J Urol 2017;

28. Calves J, Thoulouzan M, Perrouin-Verbe MA, Joulin V, Valeri A, Fournier G. Long-term Patient-reported Clinical Outcomes and Reoperation Rate after Photovaporization with the XPS-180W GreenLight Laser. Eur Urol Focus 2017; 1.

29. Vlachopoulos C, Jackson G, Stefanadis C, Montorsi P. Erectile dysfunction in the cardiovascular patient. European Heart Journal 2013; 34: 2034-2046.

30. Montorsi P, Montorsi F and Schulman CC: Is Erectile Dysfunction the "Tip of the Iceberg" of a Systemic Vascular Disorder ? European Urology 2003; 44: 352-354. 
Figure 1: Changes in PSA level $(\mathrm{ng} / \mathrm{ml})$ from baseline and at the $3^{\text {rd }}, 12^{\text {th }}, 24^{\text {th }}$ month in PVP and GreenLEP groups

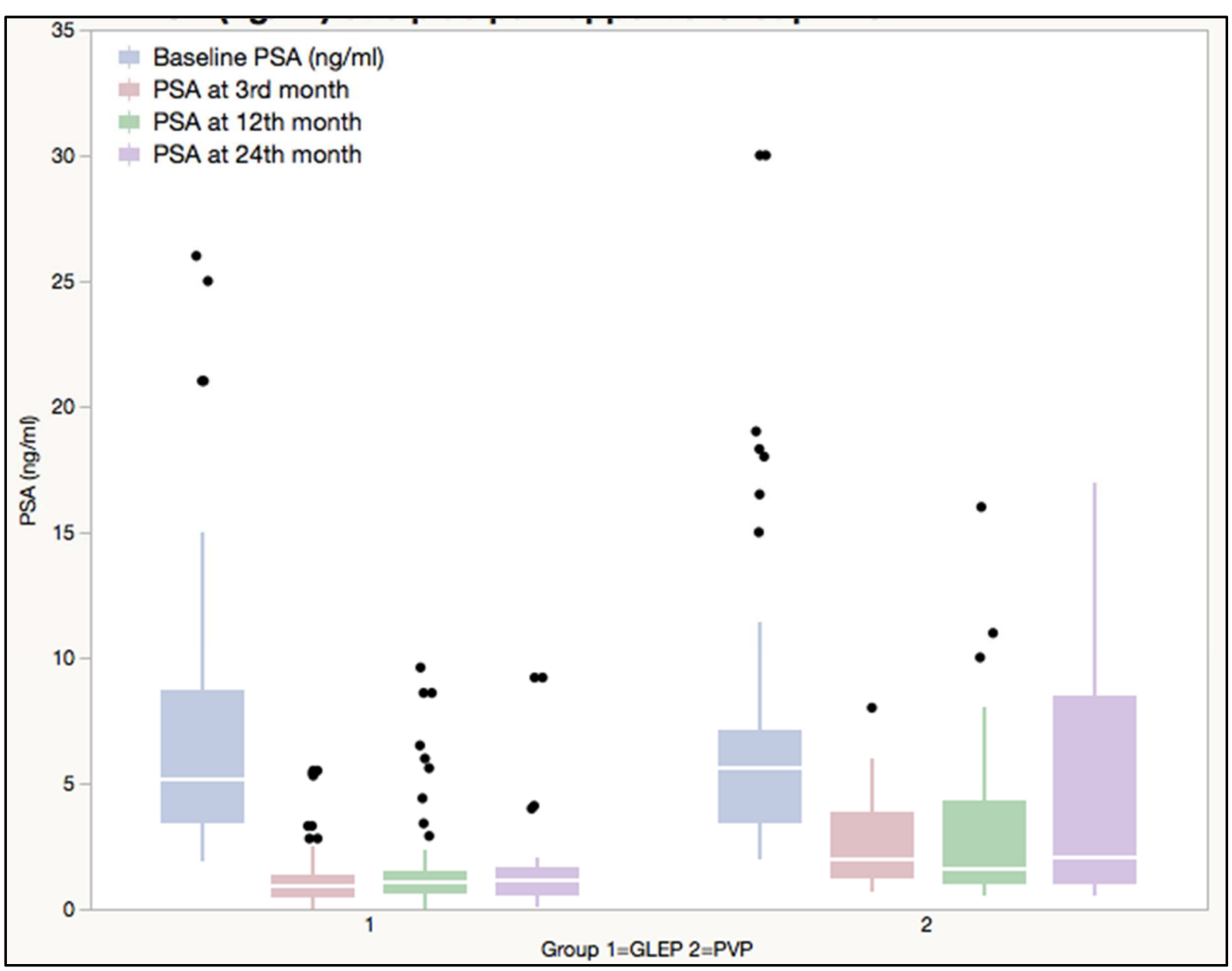


Table 1: Patients Characteristics

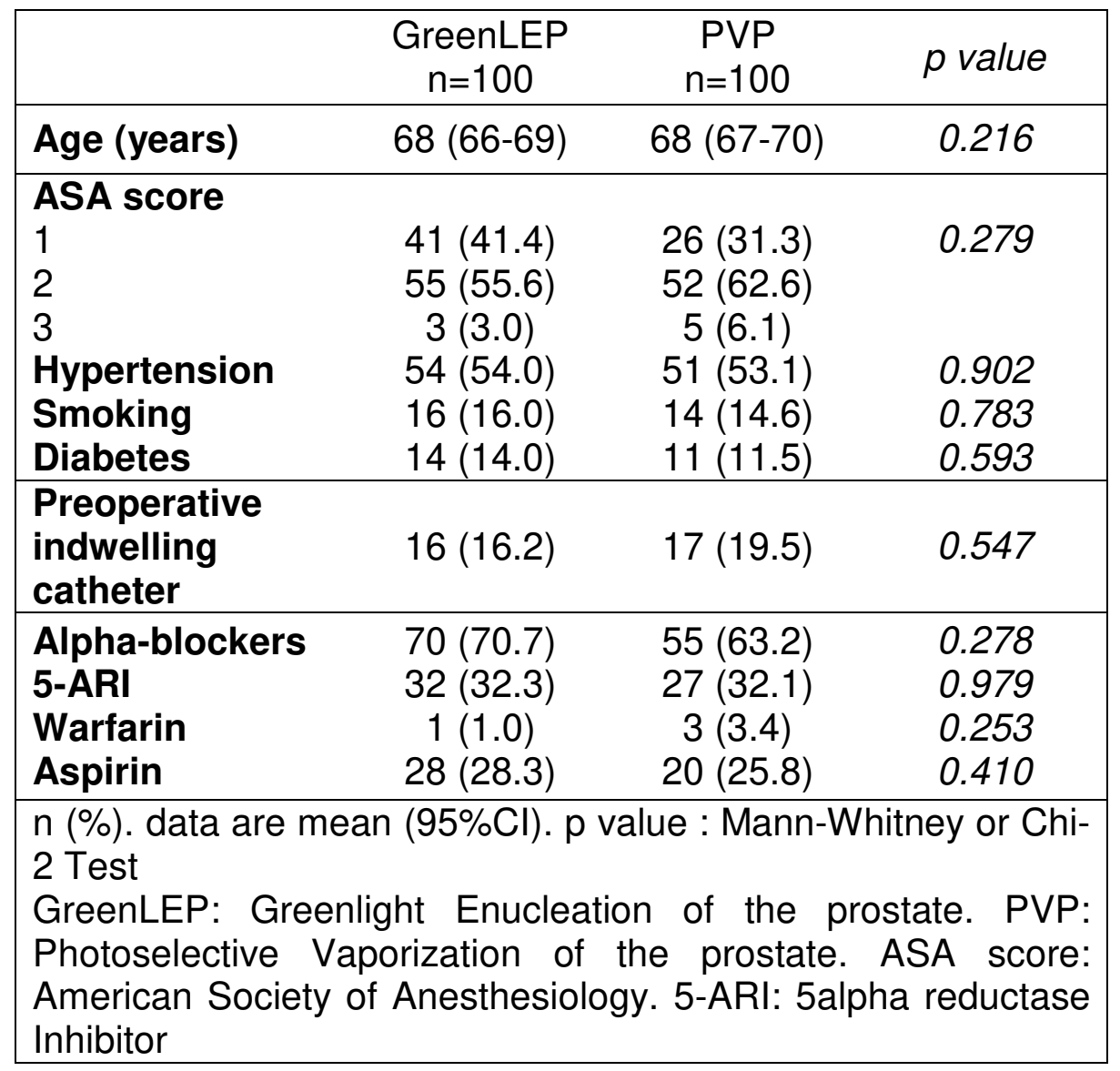


Table 2: Changes in International Index of Erectile Fonction-5 (IIEF5 score) from baseline at the third, $12^{\text {th }}$ and $24^{\text {th }}$ month of follow-up.

\begin{tabular}{|c|c|c|c|c|c|c|c|c|}
\hline & \multicolumn{2}{|c|}{ Baseline $(n=186)$} & \multicolumn{2}{|c|}{3 months $(n=151)$} & \multicolumn{2}{|c|}{12 months $(n=115)$} & \multicolumn{2}{|c|}{24 months $(n=89)$} \\
\hline & GLEP & PVP & GLEP & PVP & GLEP & PVP & GLEP & PVP \\
\hline $\begin{array}{l}\text { IIEF5 } \\
\text { score } \\
p \text { value }\end{array}$ & $\begin{array}{l}13.6 \\
\pm 6.9\end{array}$ & $\begin{array}{c}14.1 \\
\pm 6.8 \\
0.619\end{array}$ & $15.7 \pm 6.2$ & $\begin{array}{c}14.2 \pm 6.7 \\
0.123\end{array}$ & $16.3 \pm 6.5$ & $\begin{array}{c}13.2 \pm 7.1 \\
0.009\end{array}$ & $\begin{array}{l}15.8 \\
\pm 5.8\end{array}$ & $\begin{array}{c}13.2 \pm 7.1 \\
0.061\end{array}$ \\
\hline $\begin{array}{l}\Delta \text { IIEF5 } \\
p \text { value }\end{array}$ & - & - & $1.1 \pm 2.3$ & $\begin{array}{c}-0.6 \pm 3.1 \\
<0.001 \\
\end{array}$ & $1.3 \pm 2.2$ & $\begin{array}{c}-1.1 \pm 3.3 \\
<0.001\end{array}$ & $0.7 \pm 2.1$ & $\begin{array}{c}-1.0 \pm 3.3 \\
0.002 \\
\end{array}$ \\
\hline
\end{tabular}


Table 3: Univariate and multivariate logistic regression analysis for risk of postoperative IIEF5 decline $\geq 5$ points

\begin{tabular}{|c|c|c|c|c|c|c|}
\hline \multirow[t]{2}{*}{ Independent variable } & \multicolumn{3}{|c|}{ Univariate } & \multicolumn{3}{|c|}{ Multivariate } \\
\hline & OR & $(95 \% \mathrm{Cl})$ & $\begin{array}{c}p \\
\text { value }\end{array}$ & OR & $(95 \% \mathrm{Cl})$ & $\begin{array}{c}p \\
\text { value }\end{array}$ \\
\hline Age & $\begin{array}{r}2.0 \\
5\end{array}$ & $(1.11-2.15)$ & 0.001 & $\begin{array}{c}1.2 \\
2\end{array}$ & $\begin{array}{l}(1.04- \\
1.43)\end{array}$ & 0.007 \\
\hline Hypertension & $\begin{array}{r}4.9 \\
4\end{array}$ & $(1.05-23.3)$ & 0.04 & 3.6 & $(0.9-14)$ & 0.074 \\
\hline $\begin{array}{l}\text { Coronary artery } \\
\text { disease }\end{array}$ & 4.3 & $(1.03-18.3)$ & 0.045 & 3.6 & $(1.7-74.4)$ & 0.021 \\
\hline $\begin{array}{l}\text { Surgical technique } \\
\text { PVP } \\
\text { GLEP=Reference }\end{array}$ & $\begin{array}{r}15 . \\
4\end{array}$ & $(1.9-121.5)$ & 0.009 & $\begin{array}{c}12 . \\
3\end{array}$ & $\begin{array}{c}(1.5- \\
101.9)\end{array}$ & 0.019 \\
\hline$\Delta$ Nocturia $>2$ & 7.8 & $(1.9-31.7)$ & 0.004 & 3.4 & $(0.7-15.2)$ & 0.107 \\
\hline$\Delta$ IPSS $<5$ & $\begin{array}{r}1.8 \\
5\end{array}$ & $(0.51-6.75)$ & 0.347 & & - & \\
\hline $\begin{array}{l}\text { Persistent antegrade } \\
\text { ejaculation }\end{array}$ & 2.2 & $(0.2-22.7)$ & 0.499 & & - & \\
\hline \multicolumn{7}{|c|}{$\begin{array}{l}\text { n (\%). data are mean }(95 \% \mathrm{Cl}) . \mathrm{p} \text { value : Mann-Whitney between GLEP and PVP } \\
\text { groups } \\
\text { GreenLEP: Greenlight Enucleation of the prostate. PVP: Photoselective } \\
\text { Vaporization of the prostate. IPSS: International Prostate Symptom Score. BMI: } \\
\text { Body Mass Index }\end{array}$} \\
\hline
\end{tabular}

